\title{
PROTISTS PARASITIC IN THE LARVA OF THE CRANE-FLY, TIPULA SP. (Preliminary Note.)
}

BY DORIS L. MACKINNON, B.Sc., Assistant in the Zoology Department, University College, Dundee.

\section{(With 27 Text-figures ${ }^{1}$.)}

\section{Introduction.}

IN 1892 Louis Léger described three species of gregarine from the alimentary tract of the larva of Tipula: Actinocephalus tipulae, Clepsidrina longa, and Eirmocystis ventricosa ${ }^{2}$.

The object of the present note is to record the presence of certain other protists abundant in the saine host, but apparently unnoticed hitherto. Several of these offer points of special interest, the details of which I hope to publish soon.

All the larvae examined by me came from the neighbourhood of Aberdeen, and I have found them almost all parasitized to some extent ${ }^{3}$. While engaged on this piece of work, I heard from M. Alexeieff (Paris) that he had observed similar protozoa in Tipula larvae from Grenoble and the neighbourhood of Paris. Alexeieff's material was not nearly so richly infected as mine, but I have had the opportunity of seeing his preparations, and find that they contain all the forms observed by me in the larvae from Aberdeen. I should like to acknowledge here my great indebtedness to M. Alexeieff for his generosity in placing his material at my disposal, and in giving me the benefit of his large experience among the flagellate protozoa.

1 All figures drawn to scale under Zeiss comp. oc. 12 and apochromatic obj. $2 \mathrm{~mm}$.

2 C. longa has since been altered to Gregarina longa and the genus Eirmocystis corrected to Hirmocystis (vide Das Thierreich. Sporozoa. Labbé, 1899).

3 During the summer of 1911 , I examined a large number of the adult flies, but never found any trace of infection. 


\section{Description of Parasites.}

\section{Rhizopoda.}

The Rhizopoda are represented in the gut of Tipula by two small forms of Entamoeba.

1. One of these (Figs. 1 and 2) has a nucleus of the Amoeba limax type, with well-developed central caryosome and peripheral grains of chromatin contained within a very delicate nuclear membrane.

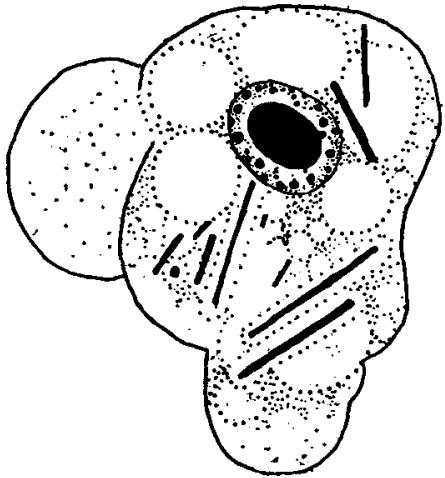

Fig. 1.

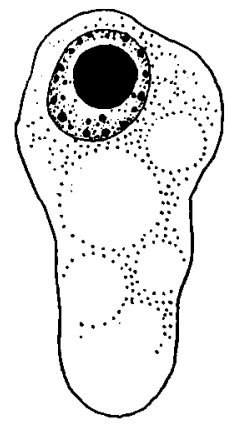

Fig. 2.

Fig. 1. Large Entamoeba with nucleus of Amoeba limax type.

Fig. 2. Small Entamoeba of same type as in Fig. 1.

2. The other (Figs. 3 and 4) resembles the entamoebae of vertebrates $^{1}$ in that its nucleus has the chromatin concentrated in an irregular layer immediately internal to the well-marked nuclear membrane, while the interior contains typically one small central chromatin granule. At times the chromatin is collected into two or three large caryosome-like masses placed excentrically (Fig. 5): such nuclei resemble closely the figures recently given by Hartmann for degenerate Entamoeba tetragena.

Both forms of amoeba have a coarsely vacuolated cytoplasm containing numerous inclusions, notably bacilli. There are usually several short, blunt pseudopodia, in the formation of which there sometimes appears a distinct severance of clearer ectoplasm from more granular endoplasm.

1 Fantham and Porter (1911) have recently recorded an entamoeba from the hive-bee (Entamoeba apis) " very like Entamgeba coli of the human intestine." 
The amoebae of the second type are sometimes parasitized by a micrococcus (cf. Nägler, 1910), accompanied by nuclear hypertrophy and other signs of degeneration.

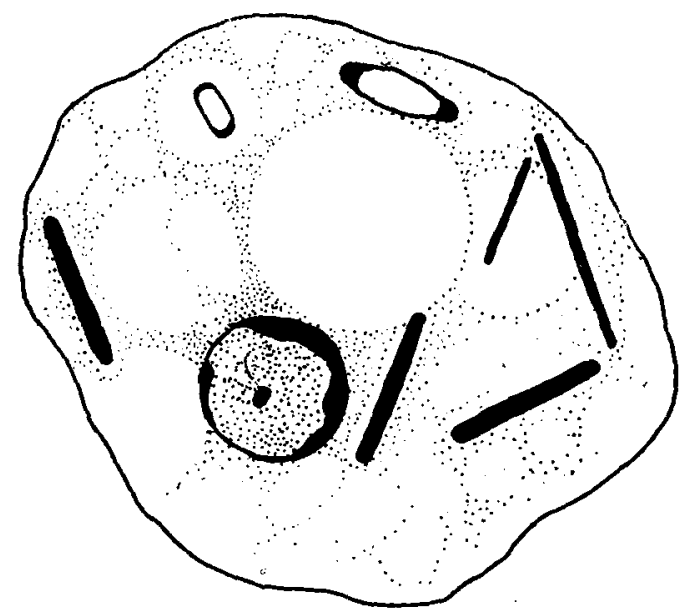

Fig. 3. Large Entamoeba with nucleus of the type found in the entamoebae of vertebrates.

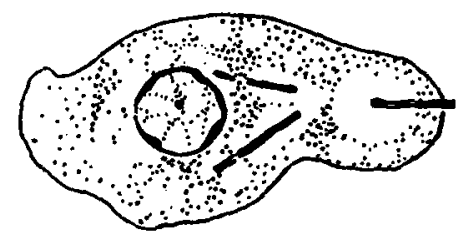

Fig. 4. Entamoeba from Tipula. Small individual of type 2.

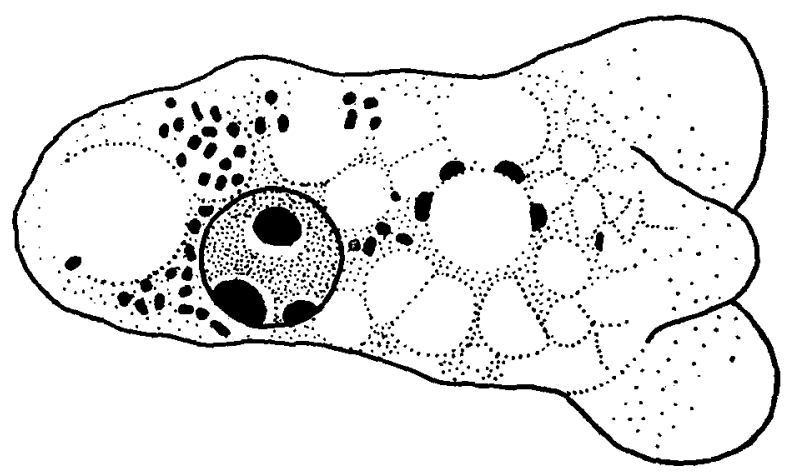

Fig. 5. Large Entamoeba of 2nd type. Here the chromatin is disposed in three excentric masses. There are numerous micrococci in the cytoplasm.

Parasitology v 


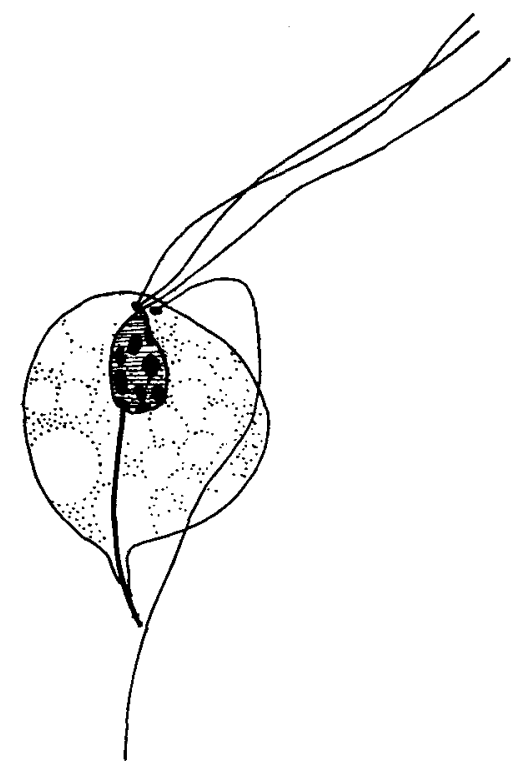

Fig. 6. Flagellate individual of Trichomastix from Tipula.

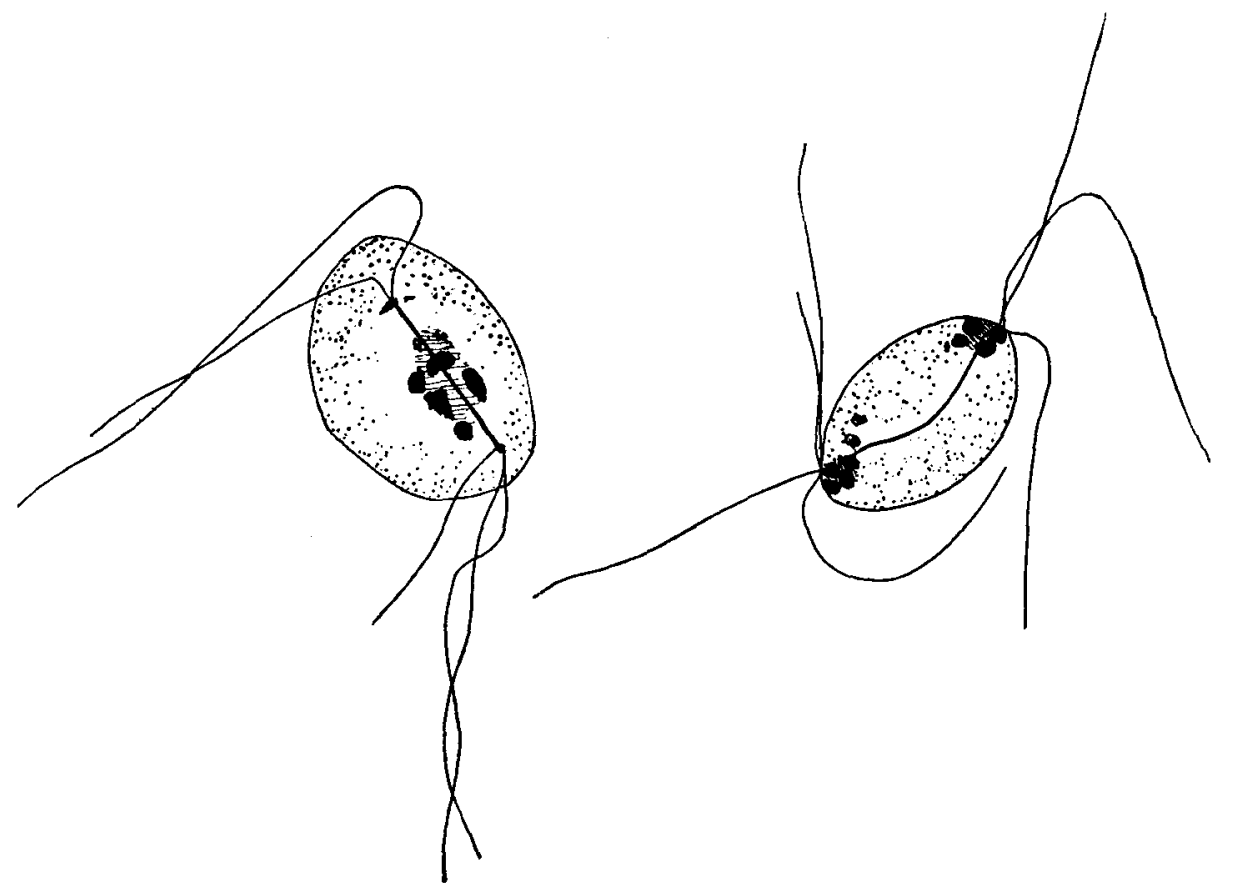

Fig. 7.

Fig. 8 .

Figs. 7 and 8. Stages in division of Trichomastix. 
There is great variability in size. The average dimensions of the entamoeba of Type 1 are $8 \mu \times 5 \mu$ with a nuclear diameter of $3 \mu$. Individuals are met measuring as much as $16 \mu \times 15 \mu$, while others are as small as $5 \mu \times 5 \mu$. Type 2 is usually rather larger than Type 1 . $16 \mu \times 17 \mu$ is a common size, with nuclear diameter of $4 \mu$. Some are as large as $25 \mu \times 22 \mu$ : others as small as $8 \mu \times 5 \mu$, or even less.

The details of division and encystment have not been worked out, and it is therefore not possible to tell yet whether there are here two different amoebae, or only two aspects of the same species. With more material at my disposal, I hope soon to settle this point.

\section{Flagellata.}

I find no less than six different flagellates in Tipula, viz. a Trichomastix, a Monocercomonas, a Polymastix, a Hexamitus, and two species of Embadomonas.

1. Trichomastix. This flagellate resembles in all important respects the trichomastix described by me from the larvae of Trichoptera. In all the stages that I have found hitherto-the ordinary flagellate individuals $(8 \mu \times 4 \mu)$, dividing forms, and multiplication (?) cysts

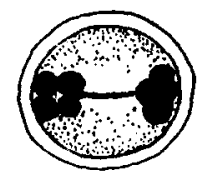

Fig. 9. Cyst of Trichomastix from Tipula.

(5 $\mu \times 4 \mu$ ) (Figs. 6, 7, 8 and 9)-this flagellate, except for its rather smaller size, is morphologically indistinguishable from T. trichopterorum Mackinnon. In the dividing flagellates and in the cysts, the chromatin shows a marked tendency to group itself into four masses (chromosomes?) at each pole.

It occurs in about $30 \%$ of the infected larvae.

2. Monocercomonas. This is a pear-shaped or spherical organism without definite periplast (Figs. 10 and 11). Its dimensions vary from $6 \mu \times 3 \mu$ to $9 \mu \times 5 \mu$. The four flagella, which appear to be of approximately equal length, are disposed in two groups of two at the anterior end of the body, the groups usually being separated from one another by a distinct space. The nucleus, which lies at the anterior end of the organism, is of the "vesicular" type, with a well-marked caryosome, 
sometimes placed excentrically, and also a few chromatin grains in the surrounding nuclear sap. There is generally a distinct group of extranuclear siderophilous granules.

The flagella can be seen to take their origin in two basal granules, which are sometimes connected by a dark-staining delicate line (Fig. 11). An axostyle is usually developed, and appears to arise from one of the basal granules. It then curves around one side of the nucleus, and runs as a slightly sinuous line to the posterior end of the body, beyond which it seldom projects. (Cf. the more rigid axostyle of trichomonads.) The vacuolated cytoplasm contains numerous inclusions, sometimes of astonishing size, considering that there is no hint of a cytostome. The flagellate is sometimes parasitized by a micrococcus.

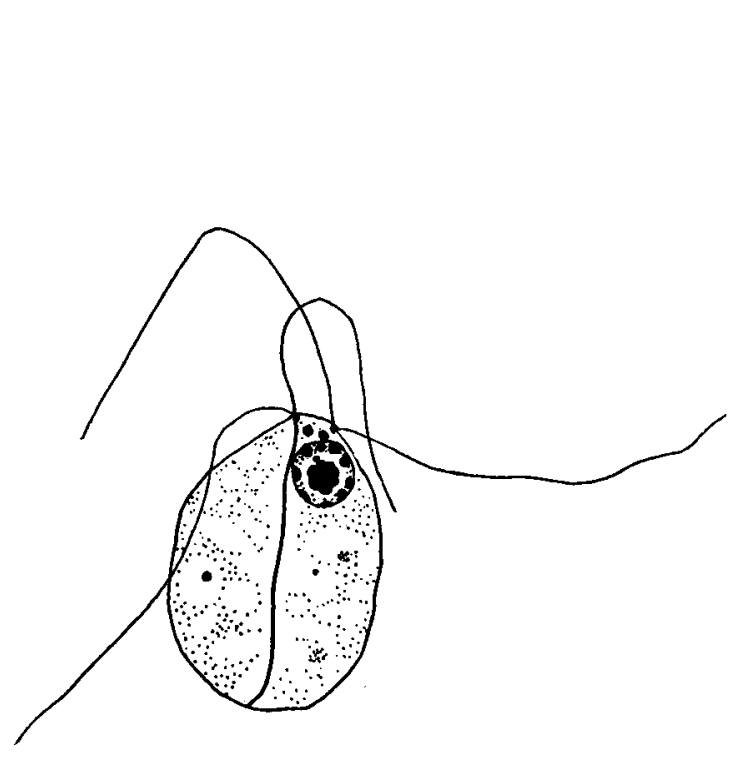

Fig. 10.

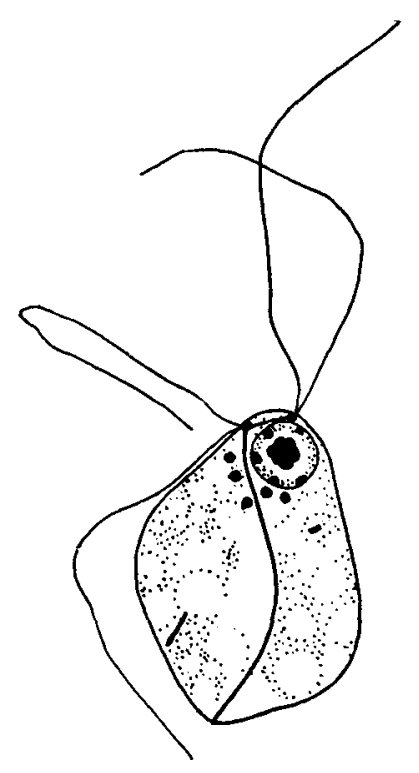

Fig. 11.

Fig. 10. Monocercomonas from Tipula. Flagellate individual.

Fig. 11. Monocercomonas. Flagellate showing connection between basal granules.

The Monocercomonas from Tipula agrees in all essentials with the closely related species M. melolonthae (Grassi) (1879) from Melolontha and Gryllotalpa, and M. cetoniae Jollos (1911)․

$1 M$. bufonis Dobell (1908), the only other well-authenticated species in this genus, differs markedly from these in having no axostyle, and in possessing a well-developed "pseudo-chromidial body." (Alexeieff, 1911.) 
In $M$. cetoniae the "outer nuclear network" is "poor in chromatin" (Jollos), and Hamburger finds that the flagella of this species show a tendency to inequality in length, and the development of a "Schleppgeissel." M. melolonthae, on the other hand, is described as having a "wohlentwickelten chromatinreicheren Aussenkern" (Jollos), and, according to Grassi, the flagella are of approximately equal length. So far as I can judge from the scanty indications in the literature, the flagellate from Tipula may be placed, at least provisionally, in Grassi's species, M. melolonthae, from which it differs only in its somewhat smaller size and the frequent presence of extra-nuclear siderophilous granules.

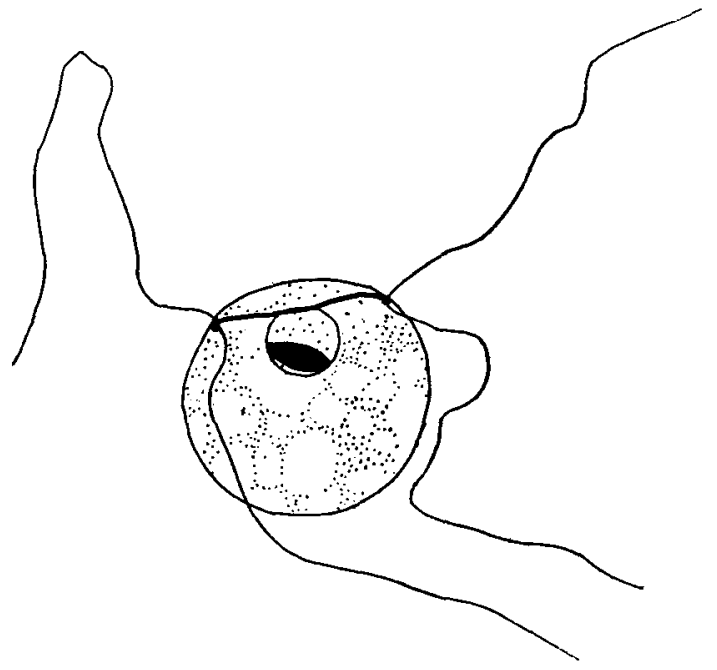

Fig. 12. Division stage of Monocercomonas from Tipula.

The division stages (Fig. 12), so far as I have studied them, agree on the whole with Hamburger's account for $M$. cetoniae.

This flagellate occurs in about $75 \%$ of the infected larvae. I have frequently observed what I consider to be its cysts.

3. Polymastic. It is interesting to find that, as in Melolontha (according to Grassi (1882) and Hamburger (1911)), and in Cetonia (according to Hamburger (1911)), the Monocercomonas of Tipula is usually accompanied by a Polymastix.

This organism, which occurs sometimes in vast numbers, is a pearshaped flagellate often forked or otherwise "deformed" posteriorly. The dimensions vary from $7 \mu \times 4 \mu$ to $15 \mu \times 6.5 \mu$ (Figs. 13 and 14). Four long fagella, approximately equal in length, spring from the anterior 
end in two groups of two. The nucleus is of the same vesicular form as in Monocercomonas, containing a caryosome composed of a number of closely-massed chromatin granules, but with very little chromatin in the space between caryosome and nuclear membrane. As in the Monocercomonas the nucleus is surmounted, and in part surrounded, by a group of siderophilous granules. In well-stained individuals it is

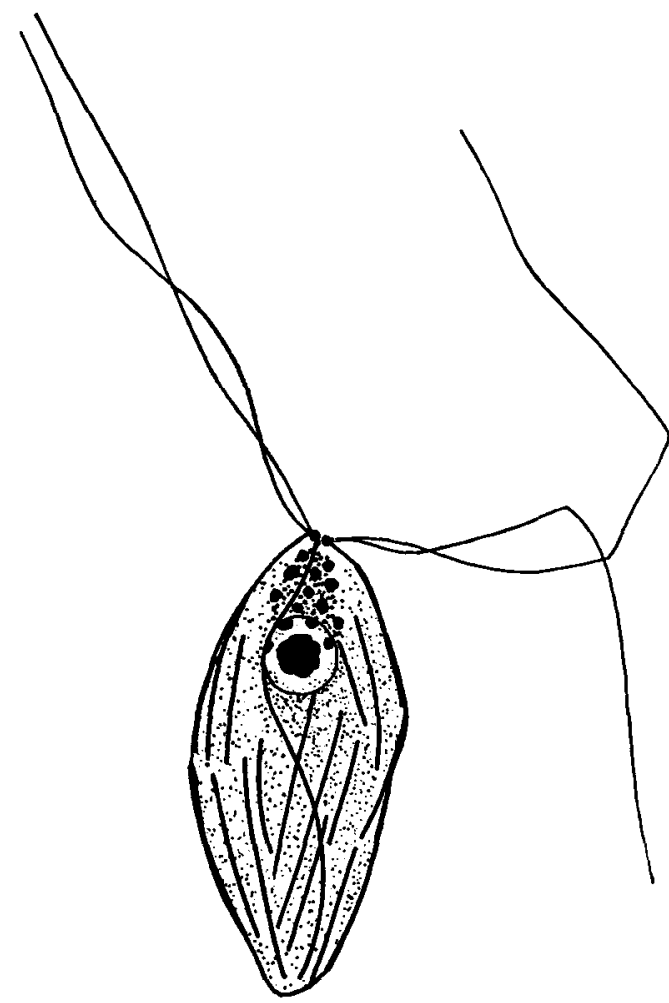

Fig. 13.

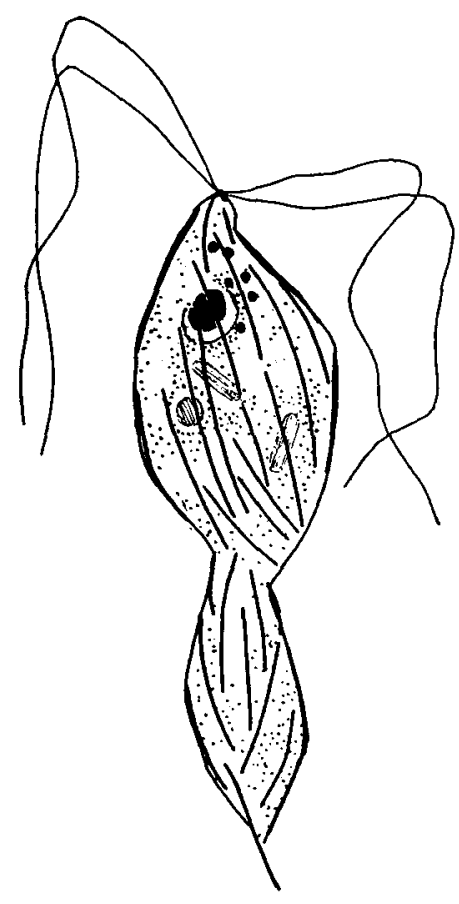

Fig. 14.

Fig. 13. Polymastix from Tipula. Large flagellate individual showing vesicular nucleus, extra-nuclear granules, axostyle, etc.

Fig. 14. Polymastix showing a characteristic posterior deformity.

generally possible to make out an axostyle of the same sort as in Monocercomonas, and bearing the same relation to the nucleus and basal granules ${ }^{1}$. In all these points, Polymastix and Monocercomonas resemble one another closely. The chief feature that distinguishes the

1 In Polymastix the nucleus is usually placed further from the anterior end than in Monocercomonas. 
flagellate individuals from one another is the periplast, which in Polymastix is well-developed, and characteristically raised up into longitudinal "ribs" or minute folds.

These "ribs," which in the living organism appear to run almost unbroken from one end of the flagellate to the other, are seen on staining to be discontinuous, and to fall into groups of shorter, darkly-staining lines inclined at various angles'. There appears to be a small cytostome between the two groups of flagella, and the cytoplasm contains ingested bacteria, etc.

In certain cases this periplast disintegrates (Figs. 15 and 16), and it seems to me not impossible that the Polymastix may, through loss of its pellicle, pass into a Monocercomonas form: in such cases, the two genera, as represented by the parasites from Tipula at least, could no longer be regarded as autonomous. A careful study of the division and encystment can alone decide whether this is the case or not. With regard to the division I can as yet say very little, but it appears to me that the axis of the division-spindle comes to lie parallel to the long axis of the body, in which case authors' statements that the division is transverse would not be far out.

The genus Polymastix was formed by Bütschli to include Grassi's Trichomonas melolonthae. So far, no reliable species have been added to the genus ${ }^{2}$, the solitary occupant of which, not examined since 1884, "bedarf dringend der Nachuntersuchung" (Dotlein, 1911). Hamburger (1911) has recently published a preliminary note, including observations on Polymastix melolonthae. She finds the same parasite also in the larvae of Cetonia. In various points, such as the presence of an axostyle and the details of nuclear structure, my flagellate differs from the

1 Grassi interpreted these structures as "trichocysts." On first seeing them, I was inclined to regard them as bacilli adherent to the body of the flagellate (cf. Künstler, 1882), or else ingested and in some way come to form a sort of thin layer just below the periplast. Various points plead in favour of this view, notably the occurrence of such individuals as that figured in Figs. 15 and 16. However, $I$ have recently abandoned the idea, and consider that Frl. Hamburger's interpretation is probably the right one-." mir scheinen es verdickte Streifen der Pellicula zu sein."

M. Alexeieff has drawn my attention to a similar appearance presented by the periplast of Lophomonas striata Bütschli, from the cockroach, recently described in detail by Janicki (1910).

It is interesting that an unstriated form, Lophomonas blattarum, lives alongside this. I believe that a comparison of Polymastix with these Trichonymphids may not be unprofitable.

2 The flagellate with six flagella and without striated periplast, placed provisionally by Alexeieff (1911) in this genus as $P$. bufonis, seems to me a very doubtful species. 
account given by Frl. Hamburger. But in iron haematoxylin preparations where the differentiation is unsatisfactory, I get much the same homogeneous nucleus as she describes, and can see nothing of the axostyle. I am inclined to regard the Polymastix from Tipula as identical with the type-species Polymastix melolonthae (Grassi).

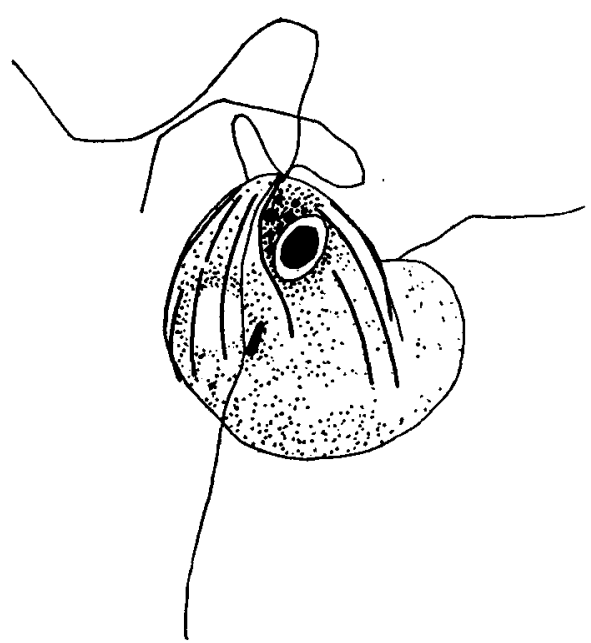

Fig. 15.

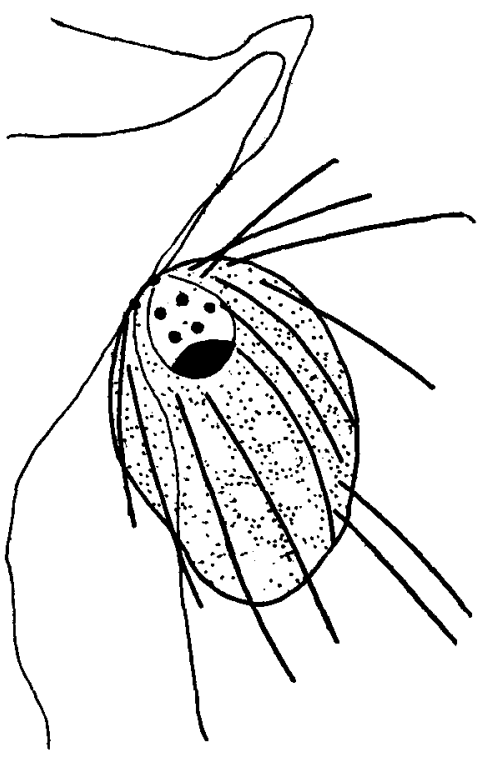

Fig. 16.

Fig. 15. Polymastix in which the hinder end has lost its characteristic ribbed pellicle.

Fig. 16. Polymastix in which the periplast is fraying off. Possibly some of these "ribs" may in this case be adherent bacteria.

4. Hexamitus. In some $10 \%$ of these infected larvae there occurs very sparingly a flagellate which is apparently Hexamitus intestinalis, or some very closely allied species (Fig. 17). It is of small size, $8 \mu \times 3 \mu$ being the maximum dimensions. Its mode of occurrence suggests that it is more or less a chance parasite, and that Tipula is not its true host. Hexamitus intestinalis has been recorded from such diverse animals as frogs, toads, tortoises, lizards and fish. It is probably one of those "facultative" parasites, which are not very fastidious as to host, and which may therefore find opportunity to develop in a great variety of situations.

2 M. Alexeieff informs me that he found it abundant on one occasion in a larva from the neighbourhood of Paris. 
5. Embadomonas. This genus, formed by me for a monoflagellate slipper-shaped organism in the larvae of Trichoptera, finds two representatives in Tipula.

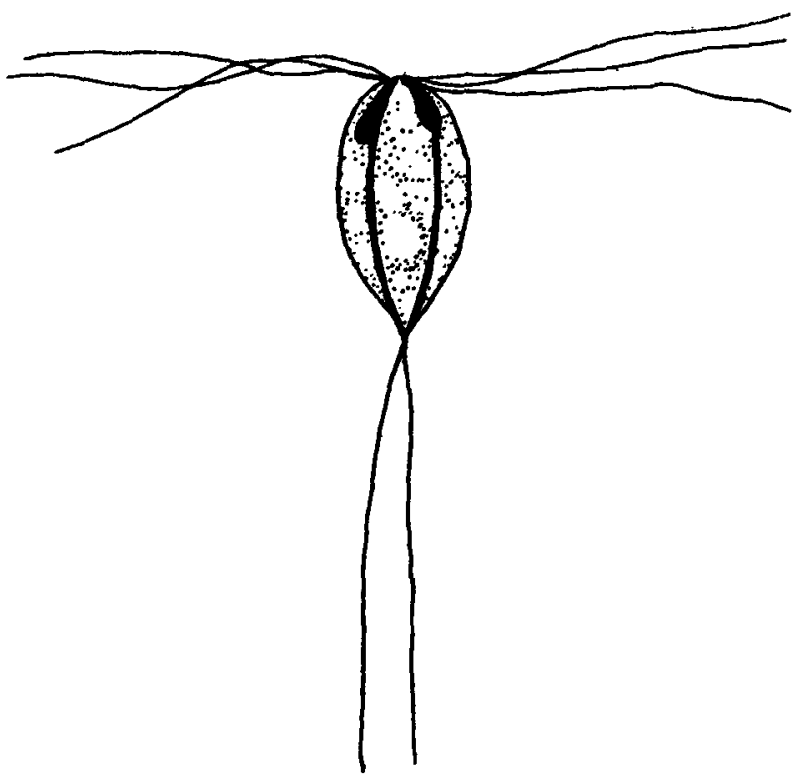

Fig. 17. Hexamitus from Tipula.

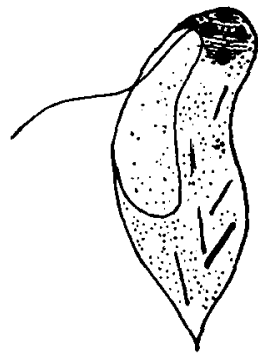

Fig. 18.

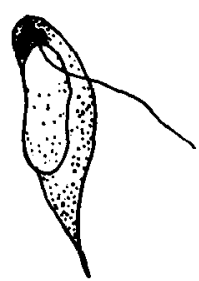

Fig. $19 a$.

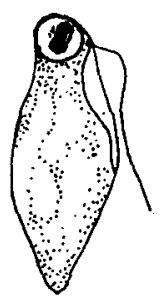

Fig. $19 b$.

Fig. 18. Embadomonas agilis.

Fig. 19 a. E. agilis. Small individual.

Fig. $19 b$. E. agilis. Individual with vesicular nucleus.

(a) The first of these is a small flagellate ( $4 \mu \times 1.5 \mu$ to $11 \mu \times 3 \mu$ ) indistinguishable from $E$. agilis Mackinnon from Trichoptera except by its rather smaller size. It has the characteristic slender slipper form, large cytostome, and anteriorly placed nucleus composed of a 
group of chromatin granules (Figs. 18 and $19 a$ ). As a rule it is possible to make out one flagellum arising from a granule on the anterior border of the cytostome. Very rarely the nucleus is of vesicular form, with a definite nuclear membrane and a central group of chromatin grains (Fig. 19 b).

The cysts (Fig. 20), now found for the first time, are minute oval bodies $(35 \mu \times 3 \mu$ to $4 \mu \times 3 \mu)$, enclosed by a double membrane, and containing a group of chromatin granules near the apex and a dark hook-shaped line in the position of the cytostome border.

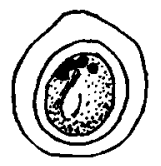

Fig. 20. Cyst of Embadomonas agilis.

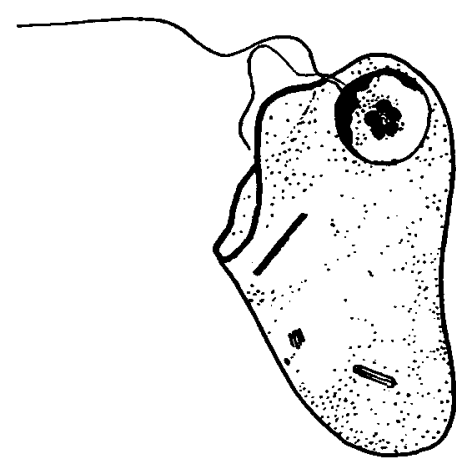

Fig. $21 a$.

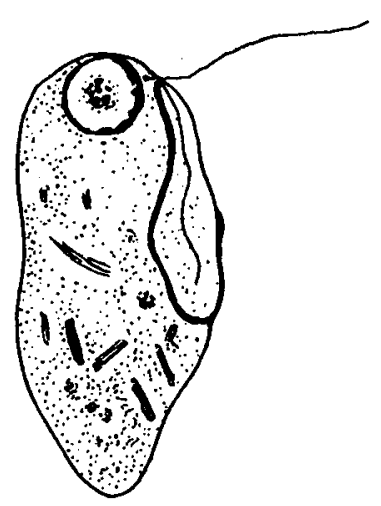

Fig. $21 b$.

Fig. 21 a. Embadomonas alexeieffi.

Fig. $21 \mathrm{~b}$. Embadomonas alexeieffi. Slender individual.

(b) Embadomonas alexeieffi n. sp. This is a larger flagellate (12 $\mu \times 8 \mu$ is a common size, while large individuals measure as much as $16 \mu \times 7 \mu$ ), of clumsier form, and with a much thicker periplast (Figs. $21 a$ and $b$ and 22). The cytostome is not quite so large in proportion as in the foregoing species, makes an angle with the long axis of the body, and has a very much more definite, deeply-staining border, often thrown into folds. The nucleus is almost always vesicular, with a definite membrane, and a central group of chromatin granules on a faint network. A deeply-staining rod-shaped or crescent-shaped mass lies against the nuclear membrane: in some cases it appears to be 
extra-nuclear. I have observed two flagella, one of which is locomotor in function, while the other generally lies within the cytostome and aids in the ingestion of food-particles. Each flagellum arises from a distinct basal granule near the anterior border of the cytostome. The highly vacuolar cytoplasm is often full of ingested bacteria. The cysts are of the same form as those of $E$. agilis, but are proportionately

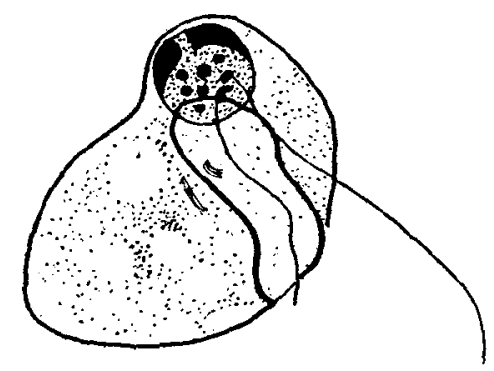

Fig. 22.

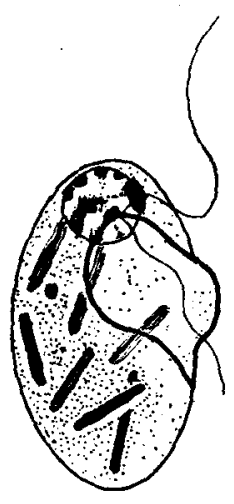

Fig. 23.

Fig. 22. Embadomonas alexeieffi. Individual with double crescent-shaped chromatin mass. Early stage of division?

Fig. 23. Kmbadomonas alexeieffi containing numerous ingested bacilli.

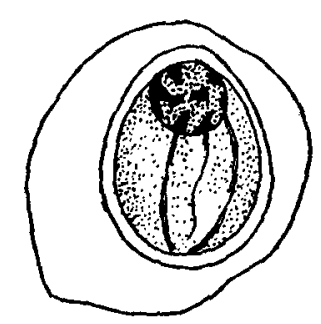

Fig. 24.

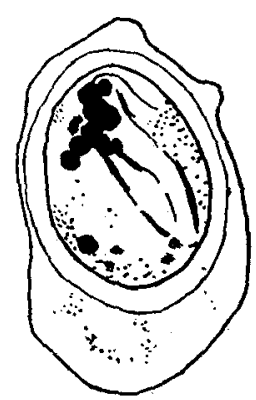

Fìg. 25.

Fig. 24. E. alexeieffi. Early stage of encystment.

Fig. 25. E. alexeieffi. Later stage of encystment.

larger $(5 \mu \times 4 \mu$ to $6 \mu \times 5 \mu)$ (Figs. 24 and 25). In the newly-formed cyst the nucleus is of the vesicular type, but it soon loses its membrane, and the chromatin escapes to form irregular groups of granules in the anterior end of the cyst. The borders of the cytostome persist as darkstaining, loop-shaped strands. There is frequently visible around the 
young cyst a delicate envelope also of oval form, within which the cyst lies excentrically. This is the periplast of the flagellate, within which the cytoplasm has contracted, surrounding itself with the true cyst membrane. This outer envelope disintegrates and disappears from the older cysts. Fig. 26 shows small oval flagellates $(3.5 \mu \times 2.5 \mu)$ probably just emerged from the cysts. I have never seen more than one flagellum in these small forms.
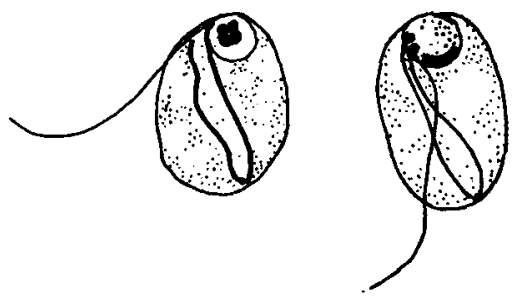

Fig. 26.

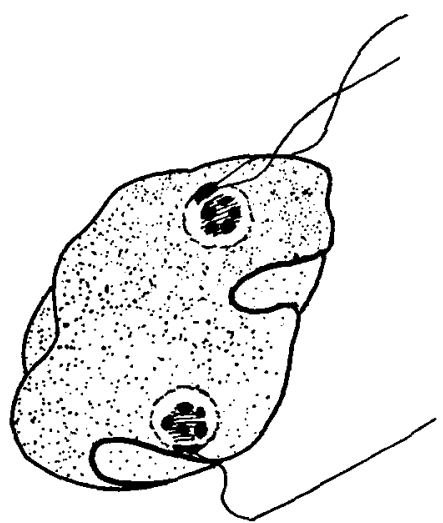

Fig. 27.

Fig. 26. E. alexeieff. Small individuals.

Fig. 27. E. alexeieffi. Stage in division.

I have observed a few division-stages of $E$. alexeieffi (Fig. 27), which agree with the figures of Robertson and Martin (1911) for the division of Chilomastix gallinarum.

I have recently had the opportunity of making a comparison between the embadomonads of Tipula and the species of Chilomastix described by Alexeieff. I am now persuaded of the close relationship between the two genera, to which Fanapepea Prowazek (1911) is probably also related .

\section{Bacteria.}

Bacteria occur in enormous quantities. Chief among them is a large sinuous form resembling Bacillus flexilis Dobell.

1 A further diagnosis of the genus Embadomonas is necessitated by the details of structure revealed in the large form $E$. alexeieffi: but I prefer to hold this over until I have worked out the life-cycle more fully. 


\section{REFERENCES.}

Alexeieff, A. (1911). Notes sur les Flagellés. Arch. Zool. exp. Ser. 6, vi. 491 527. 15 text-figs.

Bütschli, O. (1884). Bronn's Klass. u. Ordnung. 67. Protozoa.

Doflein, F. (1911). Lehrbuch der Protozoenkunde. Jena.

Fantham, H. B. and Porter, A. (1911). On a Bee Disease due to a Protozoal Parasite. (Nosema apis.) Proc. Zool. Soc. London, 1911, 625-6.

Grassi, B. (1882). Intorno ad alcuni Protisti endoparasitici. Atti Soc. Ital. S.N. XXIV.

Hamburger, C. (1911). Über einige parasitische Flagellaten. (Vorläufige Mitteilung) Verhandl. d. Naturhist. Medizin. Vereines zu Heidelberg, xI. 211-19. $1 \mathrm{pl}$.

Hartmann, M. (1912). Untersuchungen über parasitische Amöben. 2. Entamoeba tetragena Viereck. Arch. f. Protistenk. xxrv. 163-181. 2 pls, 4 text-figs.

JANICKI, C. (1910). Untersuchungen an parasitischen Flagellaten. 1 Teil. Lo. phomonas blattarum Stein, L. striatus Bütschli. Zeitschrift $f$. wissenschaft. Zool. p. 243.

Jollos, V. (1911). Studien über parasitische Flagellaten. 1. Monocercomonas cetoniae n. sp. Arch. f. Protistenk. xxiII. 311-18. 1 pl.

KüNSTLER, J. (1882). Sur cinq protozoaires parasites nouveaux. C. R. Acad. Sc. Paris. $\mathrm{xCv}$.

LEGEr, L. (1892). Tablettes zoologiques. Poitiers. virl.

Mackinnon, D. L. (1910). New protist parasites from the intestine of Trichoptera. Parasitology, riI. 245-54. 1 pl.

- (1911). On some more protozoan parasites from Trichoptera. Ibid. IV, 28-38. $1 \mathrm{pl}$. and 8 text-figs.

Martin, C. H. and Robertson, M. (1911). Further observations on the caecal parasites of Fowls. Part I. Quart. Journ. Microsc. Sc. LVII. 53-83. 5 pls. and 4 text-figs.

NÄGLER, K. (1910). Fakultativ parasitische Micrococcen in Amöben. Arch. $f$. Protistenk. xIx. 246-54. $1 \mathrm{pl}$.

Prowazek, S. v. (1911). Zur Kenntnis der Flagellaten des Darmtraktus. 1bid. xXIII. $96-100$. 16 text-figs. 